\title{
Computação Vestível em Produtos de Moda: uma abordagem centrada no usuário
}

\author{
Fashionable Computing in Fashion Products: A User-Centered Approach
}

\author{
WICK, Carla Feder. Mestranda; Universidade da Região de Joinville - UNIVILLE \\ carla_feder@hotmail.com \\ CAVALCANTI, Anna L. M. S. MsC; Universidade da Região de Joinville - UNIVILLE \\ anna.cavalcanti08@gmail.com
}

\section{Resumo}

Este artigo é parte de uma investigação em andamento no Programa de Mestrado em Design da Universidade da Região de Joinville - UNIVILLE, e apresenta, a partir de uma revisão da literatura, os conceitos da computação vestível e alguns exemplos de aplicações em produtos de moda. Discute a abordagem metodológica do HCD - Design Centrado no Humano, para o desenvolvimento de produtos de moda com a inserção da computação vestível, assim como a importância do design de interação na concepção das interfaces humano-computador aplicados nos artefatos de moda.

Palavras Chave: computação vestível, produto de moda, design centrado no humano.

\begin{abstract}
This article is part of an ongoing research in the Master's Program in Design of the University <omitted for blind reviews, and presents, from a literature review, the concepts of wearable computing and some examples of applications in fashion products. It discusses the methodological approach of HCD - Human - Centered Design, for the development of fashion products with the insertion of wearable computing, as well as the importance of interaction design in the design of human - computer interfaces applied in fashion artifacts.
\end{abstract}

Keywords: wearable computing, fashion product, human-centered design. 


\section{Computação Vestível}

Desde a antiguidade o homem criou ferramentas que facilitassem o seu cotidiano e garantissem sua sobrevivência. Segundo Pires (2005) a ciência e a tecnologia são responsáveis por aperfeiçoar o corpo e torna-lo mais próximo ao desejo do indivíduo, assim as ferramentas e instrumentos foram importantes durante o processo de evolução humana. McLuhan (2007) afirma que a instrumentalização do ser humano é uma extensão dele próprio. No processo de evolução, o corpo humano passou a ser aparelhado com o objetivo de ampliar suas funções e nesse processo se encontram as tecnologias vestíveis, consideradas uma das mais interessantes da contemporaneidade. Nessa investigação, a tecnologia vestível refere-se à dispositivos (computadores) utilizados no corpo e que promovem a interação com o indivíduo.

Conforme Donatti (2005), os dispositivos vestíveis são como computadores conectados ao corpo do usuário, sendo controlados por ele, auxiliando atividades motoras e/ou cognitivas. 0 campo da ciência que estuda os computadores vestíveis é denominado wearable computing, que pesquisa e projeta dispositivos sensoriais que utilizam o corpo como suporte. Segundo Seymour (2008), na atualidade, os corpos se tornaram extensões dos avanços tecnológicos devido ao alto grau de interação com a tecnologia. Isso ocasiona uma relação inerente com o corpo, aumentando sua mobilidade, e nessa integração a tecnologia vestível adquire cada vez mais destaque.

O acesso às informações em um dispositivo vestível acontece de forma direta e instantânea, tem a vantagem de não ser invasiva como a tecnologia móvel, por ser mais fácil de manusear e não necessitar de completa atenção do usuário para tal. A computação vestível está relacionada com áreas da computação ubíqua e com a história do desenvolvimento dessa ferramenta. Rodrigues (2008) afirma que o termo computação ubíqua foi apresentado pelo cientista Mark Weiser, chefe do centro de pesquisa Xerox PARC, no final dos anos 80. Para Weiser, computação não é exclusividade de um computador, mas sim de diversos conectados. Ela é responsável por proporcionar uma interação sutil entre computador e humano, integrando-o com ações naturais do ser humano, o que ocasiona a sensação da tecnologia ser pervasiva. Zao e Whang (2011) define computação pervasiva como invisível ao olho nu, mas reconhece-se sua presença no ambiente.

O desenvolvimento de hardwares menores permitiu ocultar os dispositivos e circuitos elétricos, proporcionando liberdade de movimentos corporais ao usuário. O uso de tecnologias em aparatos e objetos presentes no cotidiano, permitem ampliar a sua função, e a aproximação deles ao corpo possibilita auto exploração, trazendo um novo significado do próprio corpo como meio de comunicação e interação. (DONATTI, 2005)

O percursor dos estudos em computadores vestíveis, Steve Mann (1998) considera como grande diferencial dos computadores vestíveis, o fato de estarem totalmente conectados ao usuário, e atribuiu três modos básicos de operação a esses computadores, apresentados na tabela 1. 
Tabela 1: Modos Operacionais de Computadores Vestíveis

\begin{tabular}{|c|c|c|c|}
\hline \multicolumn{4}{|c|}{ Modos Operacionais } \\
\hline Constância & $\begin{array}{l}\text { O fluxo de informações deve } \\
\text { fluir de forma constante entre } \\
\text { usuário e computador; }\end{array}$ & & \\
\hline Aperfeiçoamento & $\begin{array}{l}\text { Possibilitar ao usuário executar } \\
\text { livremente suas tarefas, } \\
\text { potencializando seus sentidos } \\
\text { com a finalidade de executar } \\
\text { da melhor forma suas } \\
\text { atividades; }\end{array}$ & $\begin{array}{l}\text { Tarefa } \\
\text { cotidiano } \\
\end{array}$ & \\
\hline Mediação & $\begin{array}{l}\text { Mediar a relação do usuário } \\
\text { com o meio externo, como um } \\
\text { filtro de possíveis ameaças e } \\
\text { invasões de hardware e } \\
\text { software. }\end{array}$ & $\underset{\text { Externos }}{\stackrel{\text { Entrada }}{\longrightarrow}}$ & $\underset{\text { Externos }}{\stackrel{\text { Saida }}{\longrightarrow}}$ \\
\hline
\end{tabular}

Fonte: adaptado de Mann (1998)

Os atributos definidos por Steven Mann (ibdem) aos computadores vestíveis são: não restritivo; observável; controlável; alerta ao ambiente e comunicativo. Eles são aparatos, produtos no qual estão inseridos elementos computadorizados, desde a trama dos tecidos aos objetos de comunicação acoplados no corpo por meio das roupas; os computadores vestíveis são, portanto, vinculados ao corpo do indivíduo e agem de forma interativa com ele, executando uma tarefa enquanto o individuo que o veste, executa a outra.

Segundo McLuhan (2007) a sensibilidade das pessoas em relação ao vestuário é sentida através da pele, assim, a computação vestível amplia essa capacidade do usuário, transformando a percepção humana. Dessa maneira, o vestuário, produto de moda, adentra no campo da computação vestível ao agregar um componente computacional na roupa.

Exemplo dessa aplicação é a jaqueta criada pela empresa Google em parceria com a marca 
Levi's, o wearable Project Jacquard (FIGURA 1). A jaqueta utiliza sensores e tecidos condutivos, para mandar e receber instruções para o usuário via smartphone. Pensada incialmente para facilitar a vida dos ciclistas quando em movimento, o usuário pode receber comandos GPS, notificações de mensagens e ligações, além de controlar a reprodução de músicas por meio de gestos realizados na manga da jaqueta.

Figura 1: Jaqueta Project Jacquard

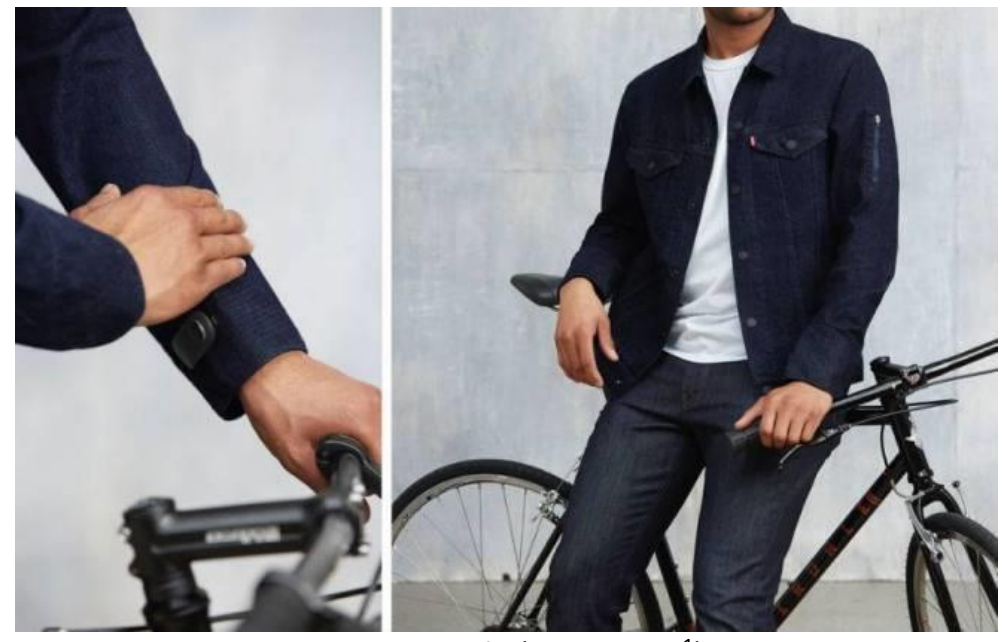

Fonte: Google (WEB, 2018 $)$

A empresa Cute Circuit de Londres, famosa por desenvolver produtos de moda com a computação vestível, criou a HugShirt (FIGURA 2), jaqueta que permite as pessoas enviarem abraços à distância. Existem sensores embutidos que simulam a força, duração e localização do toque, o calor da pele e a taxa de batimentos cardíacos do emissor. Segundo a empresa responsável pela criação, as pessoas precisam ser abraçadas pelo menos 70 vezes por dia, assim o projeto da HugShirt foi concebido, não para substituir o calor humano, mas para causar a felicidade quando a pessoa estiver ausente. O projeto tem algumas aplicações no campo da medicina com idosos e crianças.

\footnotetext{
${ }^{1}$ Disponível em <https://atap.google.com/jacquard/levi/>. Acesso em 01.abr.18
} 
Figura 2: Jaqueta Hug Shirt

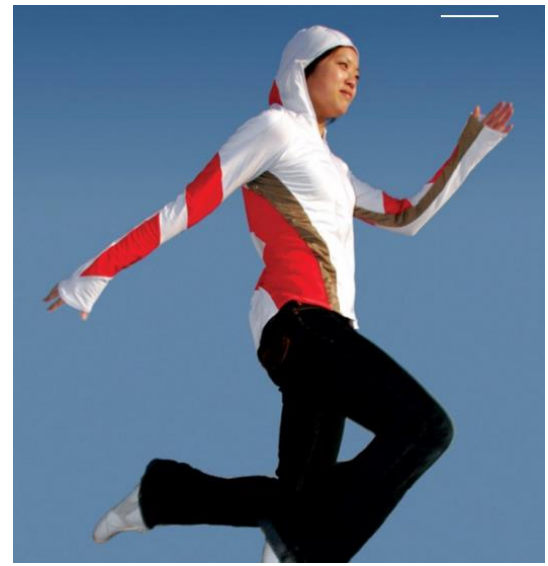

Fonte: Cute Circuit (WEB,2018²)

A computação vestível aplicada em produtos de moda promove a afluência entre o design de moda e a tecnologia, o que possibilita novos formatos de interação do vestuário com o usuário e do sujeito com a tecnologia. Ao incorporar um dispositivo computacional no vestuário, a moda embrenha no campo da computação vestível. Seymmour (2008) se referiu à intersecção do design, moda, tecnologia e ciência como fashionable tecnhnolog, essa relação descreve o conceito de um objeto agradável esteticamente, com funcionalidades avançadas, que possibilita novas interações com o usuário e do sujeito com o mundo. A autora afirma que o vestuário é uma interface imediata, sendo transmissor e receptor continuo de experiências, emoções e significados.

\section{Produto de moda centrado no humano}

No processo de design, o vestuário pode ser intitulado produto de moda. Rech (2002) atribui ao produto de moda, aquele que possui características de criação relacionadas ao design e tendências de moda, qualidades conceituais e físicas, aspectos de usabilidade e vestibilidade, aparência e preço, que vão de acordo com os anseios do mercado destinado ao produto.

O design de moda, conforme Christo (2008), aproxima o conceito de design à produção de moda, com uma troca de valores, em que o design busca na moda a sistematização dos produtos com o conceito de tendência e coleção, e a moda busca no design a conceituação de projeto, com preocupações relacionadas a usabilidade e ergonomia, de forma sustentável e sistematizada industrialmente.

Desta maneira, pode-se afirmar que o design de moda, como campo do design, rompe a ideia de um produto de moda (vestuário), focado na satisfação das necessidades econômicas, envolvendo produção e consumo, mas, centrado em atender as necessidades humanas, com a visão do design centrado no ser humano (HCD), uma visão antropocêntrica.

O autor Krippendorff (2000) afirma que o design focado nos aspectos objetivos do produto deu lugar a um design centrado no ser humano, evidenciando seu modo de ver e conviver com o mundo. De acordo com Jordan (2000), a ergonomia e seus aspectos, nas últimas décadas,

\footnotetext{
${ }^{2}$ Disponível em http://cutecircuit.com/the-hug-shirt/. Acesso em 01.abr.18
} 
passaram a constituir o processo de design, integrando conceitos de usabilidade.

Por muito tempo, o foco da usabilidade era a facilidade de uso do objeto, mas o conceito evoluiu e segundo Menezes $(2007$, p.26) "passou a ser visto como adequação entre o produto e as tarefas que ele deve desempenhar; a adequação com o usuário que o utilizará e a adequação ao contexto em que tal objeto será usado."

Trata-se de projetar para a diversidade humana, centrada na visão antropocêntrica, de maneira uniforme e abrangente, dentro de uma possibilidade de individualização, que busca um olhar primeiro sobre o usuário, percebendo suas necessidades e aspectos ergonômicos, e em seguida propõe-se o produto.

O projeto centrado no usuário é uma abordagem que considera o usuário em todas as etapas do processo. Donald Norman, em uma pesquisa de laboratório realizada em 1980, estabeleceu que na construção de um design efetivo é necessário considerar os interesses e necessidades do usuário, sendo ele o centro do projeto. (ABRAS;MALONEY-KRICHMAR; PREECE, 2004)

Krippendorff (2000) afirma que o design centrado no ser humano baseia-se no fato de que os produtos não são coisas, mas sim práticas sociais, assim, os designers deveriam preocupar-se com a forma que a as pessoas veem, interpretam e convivem com os produtos. O design centrado no humano $(\mathrm{DCH})$ precisa considerar técnicas para comunicar e interagir e promover o envolvimento de pessoas, para o entendimento dos seus desejos, anseios e necessidades que muitas vezes não é perceptível por essas pessoas.

A IDEO, empresa americana conhecida mundialmente por aplicar a metodologia centrada no humano com seus clientes, desenvolveu uma série de ferramentas estruturadas no livro/manual denominado Human Centered Design - Kit de Ferramentas. Esse método parte das lentes do desejo do usuário e examina as soluções através das lentes da praticabilidade e da viabilidade, conforme figura 3. 


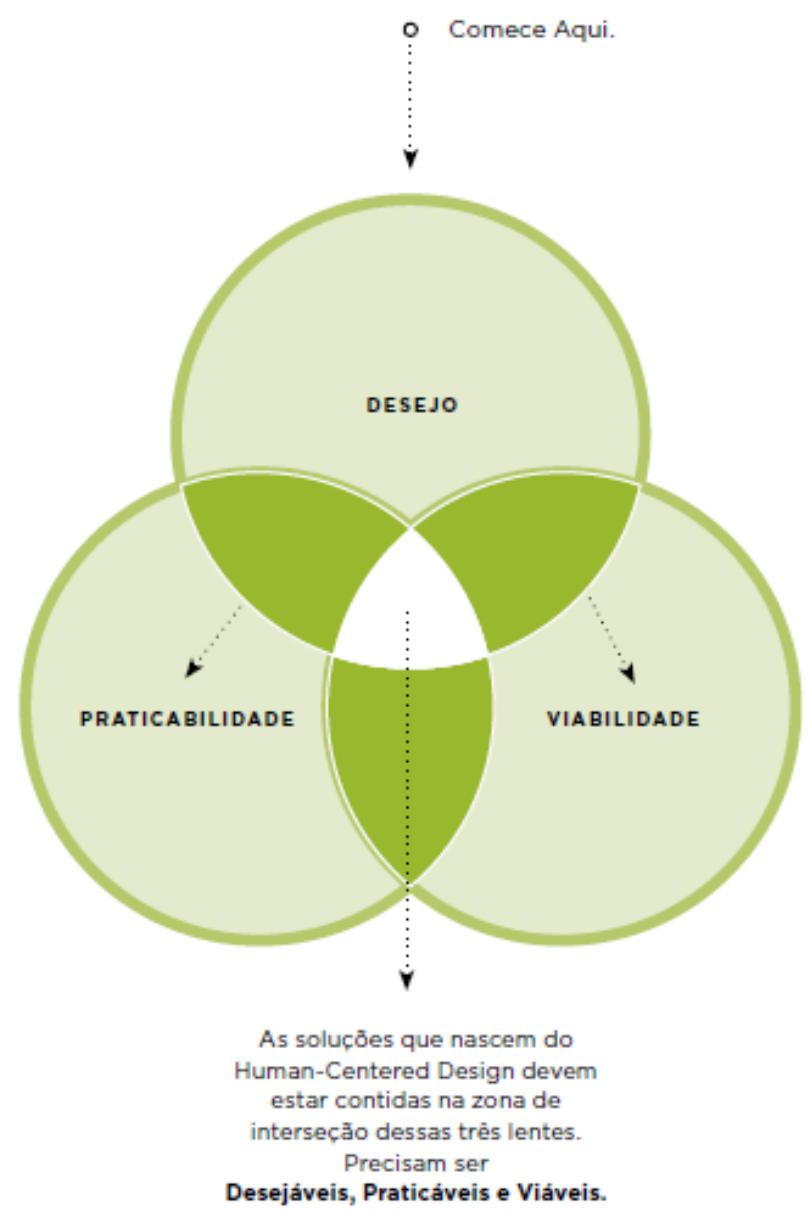

Fonte: IDEO (2009)

$\mathrm{Na}$ lente do desejo, procura-se entender as necessidades, ouvindo os desejos e observando o comportamento dos usuários, assim, depois de identificado o desejo, examina-se as propostas de soluções por meio das lentes da praticabilidade e viabilidade, sendo essas duas últimas, aproveitadas nas fases finais do projeto, servindo de auxílio no alinhamento das soluções com os desejos.

O processo da abordagem do HCD (FIGURA 4) se inicia com o desafio estratégico e segue por três etapas principais: Ouvir (Hear), Criar (Create) e Implementar (Deliver); e durante o processo o pensamento se alterna do concreto ao abstrato para identificar temas e oportunidades e depois volta-se ao concreto com soluções e protótipos. 
Figura 4: Processo do HCD

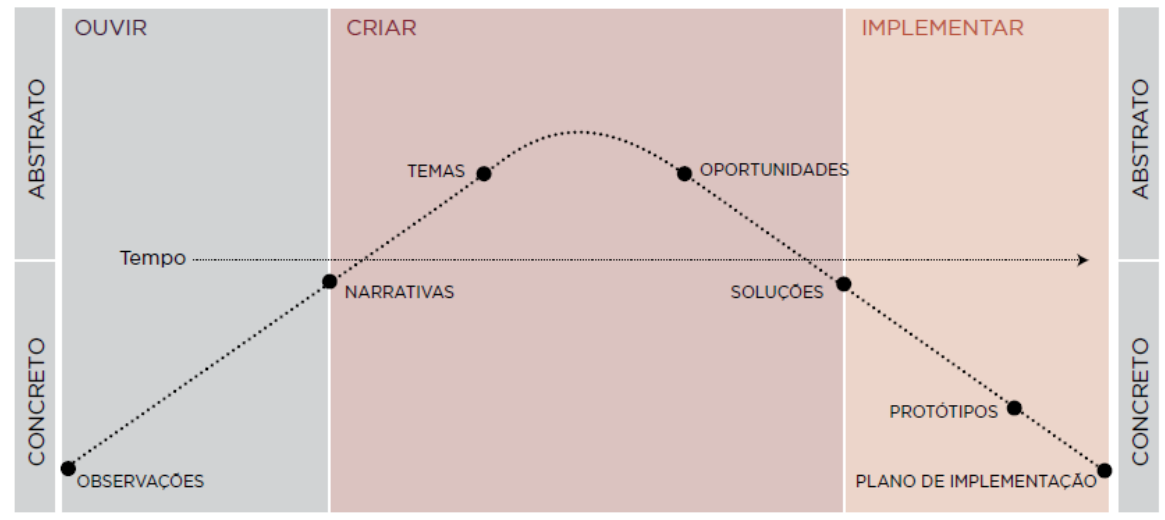

Fonte: IDEO (2009)

Essa metodologia pode ser utilizada no processo de criação de uma computação vestível em um produto de moda a partir do HCD, estruturado em 3 etapas, Ouvir, Criar e Implementar.

H - Hear (Ouvir): nessa etapa, a equipe de design precisara coletar informações, histórias e problemas relatados pelo usuário, e irá utilizar esse processo para se inspirar nas pessoas.

Brown (2008) explica que na abordagem centrada no humano (DCH), a inovação e a tecnologia devem ser fatores relacionados à necessidade, comportamento e preferências do ser humano. Portanto na etapa ouvir deve-se coletar essas informações por meio da pesquisa de campo, ouvindo e interagindo com o usuário para identificar problemas que serão solucionados na etapa seguinte, ou seja, no processo criativo de uma computação vestível, ou na adaptação de uma computação vestível em um produto de moda já existente.

C - Create (Criar): Nessa etapa a equipe deve se reunir para apresentar o que ouviu dos usuários, quais foram as dificuldades e problemas relatados, e posteriormente, identificar as oportunidades para criar as soluções e protótipos.

D - Deliver (Implementar): após a equipe de design ouvir o usuário, identificar as oportunidades e criar as soluções, é necessário implementar. Em um projeto de computação vestível, a equipe precisa planejar essa implementação. Para lançar as novas soluções, requer um planejamento dos sensores, estrutura, materiais, programação, tecnologia, interface, tudo o que será necessário para aplicar à solução.

Dispositivos de computação vestível já vêm sendo projetados com a abordagem centrada no usuário. Como o caso da BearHug (FIGURA 5), uma jaqueta criada para usuários com autismo, que simula a pressão de um abraço, e que foi projetada com base nos estudos da Deep Pressure Therapy (DPT). Mães de crianças com autismo afirmaram que seus filhos gostaram da pressão profunda e comparam a necessidade dela à mesma de oxigênio e água. (TUVIE, 2018) 
Figura 5: BearHug

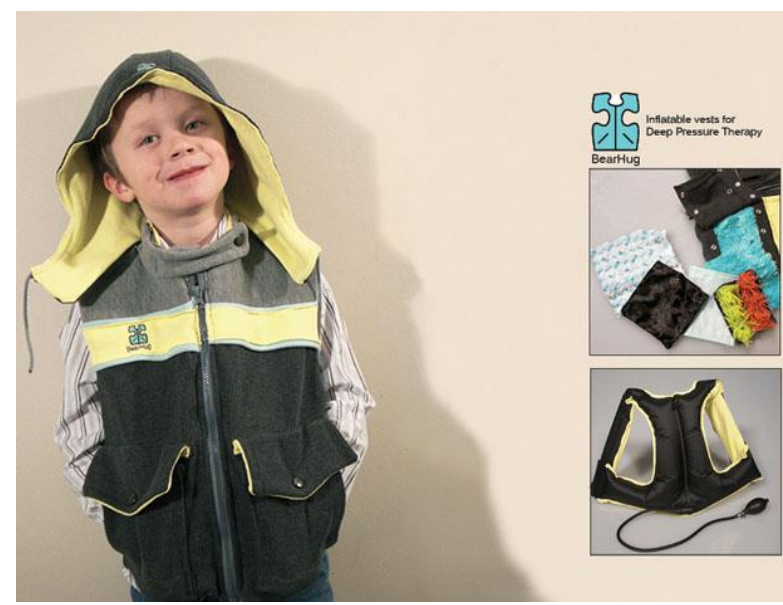

Fonte: Tuvie (WEB, 2018 ${ }^{3}$ )

A aplicação da computação vestível acontece em diversos campos. A empresa RallyPoint, de Cambrigde, EUA, desenvolveu uma luva (FIGURA 6) com sensores que permitem ao usuário controlar a navegação por mapas digitais, ativar a comunicação via rádio e enviar comandos a um computador. Este projeto foi baseado nas necessidades dos soldados militares que atuam em campo de batalha, e na impossibilidade dos mesmos largarem suas armas para executarem outras tarefas simultaneamente.

Figura 6: Luva com sensores

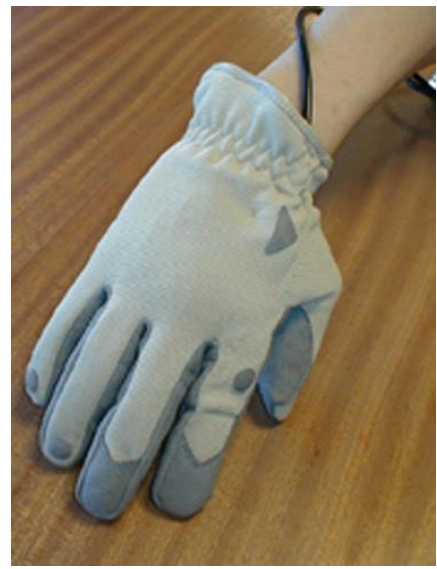

Fonte: G1 (WEB, 2018 ${ }^{4}$ )

Aplicações relacionadas à segurança e proteção do corpo também são exemplos da computação vestível a partir das necessidades dos usuários. As designers suecas Ana Haupt e

\footnotetext{
${ }^{3}$ Disponível em < http://www.tuvie.com/bearhug-inflatable-vest-has-been-designed-to-improve-the-lives-of-childrenwith-autism/> Acesso em 04.abr.18

4 Disponível em < http://g1.globo.com/Noticias/Tecnologia/0,,MUL450307-6174,00-

COM+LUVA+HIGHTECH+SOLDADO+CONTROLA+ELETRONICOS+SEM+LARGAR+A+ARMA.html>. Acesso em 04.abr.18
} 
Terese Austin desenvolveram o 'capacete invisível' (FIGURA 7), que utiliza preceitos do design de moda e tecnologia. O Hövding, nome atribuído ao capacete, é uma espécie de colar, que lembra o colar cervical, projetado com sensores que identificam uma aceleração brusca dos movimentos do ciclista, acionando o dispositivo que ejeta um colchão de ar que envolve a cabeça do usuário em uma fração de segundos.

Figura 7: Capacete Invisível

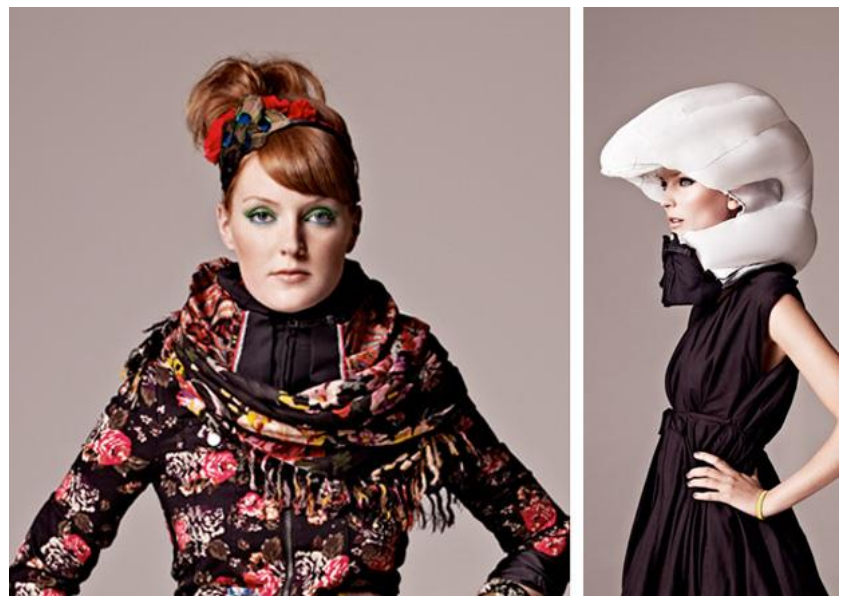

Fonte: Velojoy, $2018^{5}$

Nos exemplos apresentados, percebe-se que a concepção dos artefatos com a computação vestível foram feitas a partir das necessidades dos usuários, preceito base da metodologia centrada no humano, resultando em soluções eficientes em relação ao problema identificado inicialmente. Os exemplos apresentam uma interação sútil entre o usuário e o computador, mas o vínculo homem-tecnologia é complexo, pois necessita de uma comunicação clara e efetiva entre o usuário e o dispositivo, nesse processo o campo do design de interação responde pelo projeto das interfaces digitais, responsáveis por facilitar essa comunicação.

\section{Design de Interação na Computação Vestível de Produtos de Moda}

$\mathrm{Na}$ 'era da informação' em que se vive, tecnologias analógicas foram codificadas e pertencem ao sistema de informações das tecnologias digitais, fenômeno conhecido também como convergência das mídias. Santaella (2010) considera que todo o setor digital se fundiu em um único, unindo as quatro formas essenciais de comunicação do ser humano: o documento escrito, o audiovisual, as telecomunicações e a informática.

A convergência de tecnologias em sistemas de informação, não se resume somente em um processo tecnológico no qual une múltiplas funções e linguagens em um único sistema de informação, mas representa, principalmente, a transformação do indivíduo contemporâneo em que ele passa a ter uma participação mais ativa na conexão e controle dessas informações. As tecnologias firmam um diálogo com o seu usuário através de processos interativos. (JEKINS, 2009)

A relação homem-computador não é ferramental, por se tratar de um meio interativo, ela é complexa e comunicacional, para que esta seja efetiva, se faz necessário uma mediação por meio das interfaces digitais. (FLUSSER, 2007)

\footnotetext{
${ }^{5}$ Disponível em < https://velojoy.com/2013/07/23/another-use-for-airbag-bicycle-helmet/>. Acesso em 04.abr.18
} 
Santaella (2013) atribui a interface, como importante para a interatividade. Hoelzel (2004) define interface como o modo que a informação é organizada e como o usuário interage com essa informação. Johnson (2001) define interface como a forma pelo qual o homem se orienta nos espaços de informação, ciberespaço. Pela convergência tecnológica, as tecnologias digitais (computador), se consolidaram como agregadoras de funções que antes tinham outro suporte.

O designer é o responsável pela aproximação das tecnologias digitais, tão duras e ferramentais, do usuário, no sentido de facilitar essa relação homem-computador, utilizando as interfaces para promover a interação entre sujeito e computador. Devido à quantidade excessiva de informação atualmente disponibilizada pelas tecnologias, se faz necessário que o designer adote princípios de usabilidade e acessibilidade nos projetos de interfaces.

Preece et al (2005) define o design de interação como um processo de design de produtos interativos, que visam fornecer suporte as tarefas cotidianas do usuário. Nesse processo, lógico e criativo, consideram-se três princípios iniciais: o usuário, sendo quem usará o produto; os meios que serão utilizados para realizar a tarefa, que são as tecnologias e os métodos; e o contexto, no qual existem diversas variáveis.

Com os avanços tecnológicos e o surgimento de novas possibilidades de interação com o usuário, surgem interfaces tangíveis, por meio de objetos físicos com propriedades digitais. No caso dos computadores vestíveis, os dispositivos com propriedades digitais, controlados e reprogramáveis pelo usuário, podem ser vestidos, estendendo o conceito de aparelhos móveis, tornando-se uma extensão do corpo do usuário.

O surgimento desses novos dispositivos incorporados e imperceptíveis, ganham espaços em diversos setores do cotidiano, adquirindo força a partir da internet das coisas (IoT). Vermesan e Friess (2013) explicam a loT como um paradigma que considera a presença propagativa de coisas e objetos através da conexão sem fio, capaz de interagir e cooperar com outros dispositivos e/ou objetos, ao qual permite criar novos serviços e aplicações para alcançar objetivos comuns.

$\mathrm{Na}$ computação vestível, o desafio do designer de interação é utilizar os conceitos de usabilidade e acessibilidade para facilitar a interação do usuário com estes novos dispositivos, o que passa pelo envolvimento de uma abordagem centrada no humano que possa concretizar uma experiência, incialmente, sem seguir fundamentos sólidos.

Preece et al (2005) afirma que o design de interação permite criar experiências que melhoram e estendam a forma das pessoas trabalharem, se comunicarem e interagirem. Dessa maneira, na computação vestível a busca por inovação na experiência do usuário, com empatia e usabilidade é um requisito fundamental para proporcionar eficácia nas formas de interação.

Projetar computadores vestíveis requer testes de usabilidade relacionados ao conforto, mobilidade e também a adaptação do usuário às interfaces dos dispositivos. $O$ primeiro ponto a considerar no desenvolvimento é a questão ergonômica, porém pode ocorrer a limitação de conhecimentos expressos pelo computador. Pesquisadores já demonstraram que o corpo humano possui conhecimentos tácitos difíceis de expressar e computar pelo modo cognitivo de interação, um exemplo é o ato de amarrar os sapatos, uma tarefa difícil de se explicar em palavras, mais fácil quando utiliza-se o corpo diretamente para explica-la; como esta, existem diversos comportamentos humanos que são difíceis de ser computados.

A computação vestível procura superar esses problemas trazendo o computador para próximo 
do corpo, e também por meio de aplicativos para processar os dados contextuais gerados tendo o corpo como referência. Assim as interfaces que proporcionam a interação humano-computador precisam ser fáceis de operar, não exigindo atenção total do usuário, podendo até utilizar os sentidos como a visão e o tato para operá-las.

Ao considerar uma abordagem centrada no humano nos projetos de uma computação vestível para solucionar um problema focado nas necessidades do usuário, a interface precisa ser concebida para ser interativa, intuitiva e fácil.

\section{Considerações Finais}

Os estímulos capazes de causar o ato de perceber e sentir a realidade que circunda o usuário são variados, e uma delas é o vestir. Ao vestir uma peça de roupa, ou qualquer produto de moda, o usuário utiliza essa interface para interagir com o ambiente em que está inserido; neste ato os dispositivos de computação vestíveis se apresentam como uma possibilidade de promover e ampliar o corpo humano, seja na execução de tarefas cotidianas, na atuação do controle de sintomas de doenças, ou em suas diversas aplicações.

Toda interação, inicialmente surge de um corpo humano e afeta outro corpo humano, mesmo que não proporcionalmente, assim o ser humano precisa sempre ser considerado, inclusive em projetos de computação vestível.

O HDC, metodologia proposta pela IDEO, coloca o ser humano no centro de todo processo, e como apresentado nos exemplos descritos neste artigo, os projetos de computação vestível em produtos de moda, a partir desta abordagem metodológica, podem ter uma eficácia maior na resolução das necessidades apontadas pelos usuários.

O campo da computação vestível é inter, multi e transdisciplinar; envolve vários profissionais no processo de criação e desenvolvimento, cujo papel do designer é pensar nos requisitos indispensáveis para que os produtos sejam acessíveis, intuitivos, eficazes, de simples interação e focado nas necessidades do usuário, a fim de facilitar o contato desses com os sistemas computacionais.

Essa temática vem despertando grande interesse, com um vasto campo de atuação, mas com grandes desafios e um caminho longo a percorrer para sua comercialização. Com a popularização da computação vestível, pesquisas serão necessárias para entender as incertezas naturais decorrentes das propostas inovadoras. A investigação em andamento no metrado em design utilizará a abordagem metodológica do HCD, utilizando a pesquisas de campo (OUVIR), para o desenvolvimento de um produto de moda com a aplicação da computação vestível (CRIAR), a fim de solucionar as necessidades identificadas de um grupo de pessoas com uma deficiência específica (IMPLEMENTAR).

\section{Referências}

AVELAR, S., 2009. Moda: globalização e novas tecnologias. São Paulo: Estação das Letras e Cores. BRAGA, João. História da moda: Uma narrativa. São Paulo: Anhenbi Morumbi,2004.

CHRISTO, Deborah Chagas; PRECIOSA, Rosane. Designer de moda ou estilista? Pequena reflexão 
sobre a relação entre noções e valores do campo da arte, do design e da moda. In: Design de Moda: olhares diversos / Dorotéia Baduy Pires (org.). Barueri: Estação Das Letras e Cores Editora, 2008.

DONATI, Luisa Paraguai. O computador como veste-interface: (re)configurando os espaços de atuação. Tese de doutorado em Multimeios, Universidade Estadual de Campinas, 2005. Disponível em: <http://www.bibliotecadigital.unicamp.br/ document/?code=vtls000343013\&fd=y> Acesso em 27.mar.18

FLUSSER, V. O mundo codificado: por uma filosofia do design e da comunicação.São Paulo: Cosac \& Naify, 2007.

HOELZEL, Carlos. Design ergonômico de interfaces gráficas humano-computador: um modelo de processo. 2004. Tese (Doutorado) - Engenharia de Produção, Universidade Federal de Santa Catarina, Florianópolis, 2004.2 Disponível em < https://repositorio.ufsc.br/xmlui/handle/123456789/87671> . Acesso em 27.mar.18

IDEO. HCD - Human Centered Design: Kit de ferramentas. EUA: Ideo, 2009. 102 p. Disponível em: <http://www.ideo.com/work/human-centered-design-toolkit/>. Acesso em 24.mar.18.

JENKINS, H. Cultura da Convergência. São Paulo: Aleph 2009.

JOHNSON, Steven. Cultura da Interface: Como o computador transforma nossa maneira de criar e comunicar. Rio de Janeiro: Jorge Zahar Editor, 2001

KÖHLER, Carl. História do Vestuário. São Paulo: Martins Fontes, 2005.

KRIPPENDORFF, Klaus. Design centrado no usuário: uma necessidade cultural. Estudos em Design, Rio de Janeiro, v. 8, n. 3, p. 87-98, 2000.

MANN, Steven. Definition of wearable computer, 1998. Disponível em: < http://wearcam.org/wearcompdef.html >. Acesso em 27.mar.18

MCLUHAN, Marshall. Os meios de comunicação como extensões do homem. São Paulo: Cultrix, 2007.

MENEZES, Cristiane Schifelbein de. Design \& emoção: sobre a relação afetiva das pessoas com os objetos usados pela primeira vez. 2007. Dissertação (Mestrado em Design). Pontifícia Universidade Católica Do Rio De Janeiro - Puc-Rio, Rio de Janeiro, 2007

PIRES, Beatriz Ferreira. O Corpo como Suporte da Arte: piercing, implante, escarificação, tatuagem. Editora Senac São Paulo, 2005.

PREECE, J.; ROGERS, Y.; SHARP, H. Design de Interação: Além da Interação HomemComputador. Porto Alegre: Bookman, 2005

RECH, Sandra Regina. Moda: por um fio de qualidade. Florianópolis: UDESC, 2002.

SANT'ANNA, Mara Rúbia. Teoria de moda: sociedade, imagem e consumo. São Paulo: Estação das Letras, 2007.

SANTAELLA, Lucia. Comunicação ubíqua: repercussões na cultura e na educação. São Paulo: Paulus, 2013.

SANTAELLA, Lucia. Cultura e artes do pós-humano: da cultura das mídias à cibercultura. 4 ed. - 
São Paulo: Paulus, 2010.

SEYMOUR, Sabine. Fashionable Technology. The Intersection of Design, Fashion, Science, and Technology. New York: Springer, 2008.

VERMESAN, Ovidiu; FRIESS, Peter. Internet of Things: Converging Technologies for Smart Environments and Integrated Ecosystems. Dinamarca: River Publishers, 2013

Zhao, R., Whang, J. Visualizing the research on pervasive and ubiquitous computing. Scientometrics. n. 86, p. 593-612, 2011. http://dx.doi.org/10.1007/s11192-010-0283-8 